\title{
Seasonal Variation in Habitat Selection by Free-Ranging Feral Horses Within Alberta's Forest Reserve
}

\author{
Tisa L. Girard, ${ }^{1}$ Edward W. Bork, ${ }^{2}$ Scott E. Nielsen, ${ }^{3}$ and Mike J. Alexander ${ }^{4}$
}

Authors are ${ }^{1}$ Graduate Research Assistant and ${ }^{2}$ Professor \& Mattheis Chair in Rangeland Ecology and Management, Department of Agricultural, Food and Nutritional Science, University of Alberta, Edmonton, AB T6G 2P5, Canada; ${ }^{3}$ Assistant Professor, Department of Renewable Resources, University of Alberta, Edmonton, AB T6G 2H1, Canada; and ${ }^{4}$ Provincial Rangeland Specialist, Alberta Environment and Sustainable Resource Development, Lands Division, Pincher Creek, AB TOK 1 W0, Canada.

\begin{abstract}
Little is known about habitat selection by free-ranging feral horses in Montane environments, including how horse use may vary seasonally throughout the year. We tracked four global positioning system collared horses in four separate harems between November 2008 and October 2010 for a portion of the Rocky Mountain Forest Reserve in southwest Alberta, Canada. We assessed seasonal habitat selection for the study period by combining locational data with landscape data (including vegetation types) in an information theoretic framework. Home ranges for horses varied from 12.4 to $90 \mathrm{~km}^{2}$ and were confined to local watersheds. Horses selected most for lowland grasslands across all seasons, with shrublands increasingly selected in spring and summer. Harvested conifer forests were only selected by horses during winter. Resource selection functions indicated that in addition to vegetation type, horses were selecting for a variety of habitat characteristics (i.e., distance to forest and solar radiation), while water availability, topographic accessibility, and disturbance features (e.g., distance to roads, recreational trails, and seismic lines associated with energy exploration) had little or no influence on horse selection. Overall, horses demonstrated selection for habitats covering $14 \%$ of the study area while avoiding $42 \%$ of habitats: remaining areas were used in proportion to their availability. Concentration of horse use within sparse vegetation types (grassland and shrubland), particularly during one or more times of the year, help identify critical horse habitat including areas where multiple, overlapping land uses interact on public land.
\end{abstract}

Key Words: disturbance corridors, geographic information system, landscape features, thermal protection, vegetation type, water availability

\section{INTRODUCTION}

Following the Pleistocene mega-faunal extinction, domestic horses (Equus ferus callabus) were introduced to North America in the 1500s (Lever 1985; Singer 2005). Feral herds of free-ranging horses now occupy large parts of the western United States and portions of Canada. Horse management has received significant attention and led to the implementation of protective legislation in both the United States (Bureau of Land Management 2011) and recently, select regions of Canada (Government of Saskatchewan 2009). This political intervention has led to prominent increases in horse populations and in some instances to declines in herd health and range condition (Humane Society of the United States 2005).

In the foothills of southwest Alberta, free-ranging feral horses have been present since the early 1900s (Government of Alberta 2011). While many of these horse populations originated from unwanted and released draught animals that

\footnotetext{
Funding for this project was provided by a Ministerial grant to Edward W. Bork from Alberta Sustainable Resource Development, the University of Alberta, the Rocky Mountain Forest Range Association, and an ACA - Biodiversity Challenge Grant to Tisa L. Girard.

Correspondence: Edward W. Bork, Dept of Agricultural, Food and Nutritional Science, University of Alberta, Edmonton, AB T6G 2P5, Canada. Email: edward.bork@ ualberta.ca
}

Manuscript received 9 July 2012; manuscript accepted 26 February 2013.

(c) 2013 The Society for Range Management evaded capture attempts in the 1920s, they have been supplemented by released or escaped individuals, as evidenced by the presence of horses with brands. Feral horse populations in this region have increased from approximately 700 head in 2009 to over 1000 head in 2011 (Alberta Sustainable Resource Development [ASRD], unpublished data). These numbers represent numerous harems containing one stallion with multiple mares and foals (McCort 1984; Linklater et al. 1999). In Alberta, harems typically consist of 3 to 17 animals (Salter and Hudson 1982). Increases in the horse population, coupled with declines in the availability of grassland habitat, have raised concerns over the long-term conservation of horses and their primary habitats.

Habitat selection and use by herbivores is influenced by many factors (Anderson 2010). In addition to population size, the spatial and temporal patterns of habitat use by herbivores are important considerations (Senft et al. 1987), particularly in environments with strong seasonal variability such as northern temperate forests. In the predominantly forested foothills of Alberta, horses prefer open grasslands and shrublands during summer (Girard et al. 2013), which may reflect their preference for herbaceous vegetation over browse (Salter and Hudson 1979). Horses are also known to select areas with greater biomass to enhance foraging efficiency (Fleurance et al. 2009). In heavily forested environments that lack grasslands, horses select disturbed areas such as road side edges and seismic lines (i.e., linear clearings used for energy exploration) where grass production is high (Irving 2001). Although low water 
availability will reduce habitat selection by horses (Stevens 1988), the effects of water availability on horse use in Alberta appear to be minimal. Responses vary from positive associations in summer (Girard et al. 2013) to no particular influence throughout the year (Salter and Hudson 1979).

Terrain is also known to influence habitat selection, with horses more likely to occupy flat pastures or gently sloping ridgetops (Ganskopp and Vavra 1987). Accessibility plays a key role in regulating animal movement due to associated effects on energy expenditure (Senft et al. 1987). In rugged topography or dense vegetation, the presence of roads and trails can increase accessibility, thereby increasing use of habitats in close proximity to these corridors. However, increased human presence along roads and trails (i.e., motor vehicles, recreational vehicles, hikers, etc.) may decrease use of these habitats, as it has for wildlife (Laliberte and Ripple 2004). The net impact of corridors on feral horses in forested rangelands remains unknown. Finally, animal exposure to habitats at a young age can positively influence future habitat use (Bailey et al. 1996; Launchbaugh and Howery 2005). Harems remain loyal to a home range once established and frequently follow examples set by older animals (McCort 1984).

The eastern slopes of the Rocky Mountains contain high spatial and temporal variability in habitat availability for freeranging herbivores (Hebblewhite 2005). Given the importance of grasslands to biodiversity in the region, a greater understanding is needed of habitat selection and use by free-ranging feral horses. The objective of this study was to use global positioning system (GPS) technology to 1) quantify habitat selection by feral horses within a foothill landscape of southwest Alberta, including seasonal changes in selection, and 2) evaluate potential mechanisms influencing spatio-temporal variation in habitat selection by feral horses, including the role of vegetation type, topography, water availability, travel corridors, distance to forest, and thermal characteristics.

\section{METHODS}

\section{Study Area}

Feral horses were studied in a $202-\mathrm{km}^{2}$ area west of Bragg Creek, Alberta, in and around the McLean Creek Forest Land Use Zone of the Rocky Mountain Forest Reserve (RMFR; Fig. 1). The RMFR is an area of public land managed for multiple uses, including wildlife management, forest harvest, cattle grazing, and recreation and watershed protection, among others. Landscapes in the area fall within the Montane and Subalpine Natural Subregions, with elevations ranging from 1341 to $2331 \mathrm{~m}$ (Natural Regions Committee 2006). Vegetation consists of a mosaic of sparse grasslands and riparian shrublands along valley bottoms, with uplands comprising occasional deciduous or mixedwood forests, widespread conifer forests, and numerous harvested conifer forests, or cutblocks (ASRD 2005). The area comprises $69 \%$ conifer forest, $13 \%$ conifer cutblocks, $4 \%$ mixedwood forest, $4 \%$ shrubland, and $4 \%$ grassland, with the remainder made up of water, rock (including alpine), or heavily disturbed areas. Plant communities vary widely in herbage production, but generally follow the ranking of: grasslands $>$ shrub-

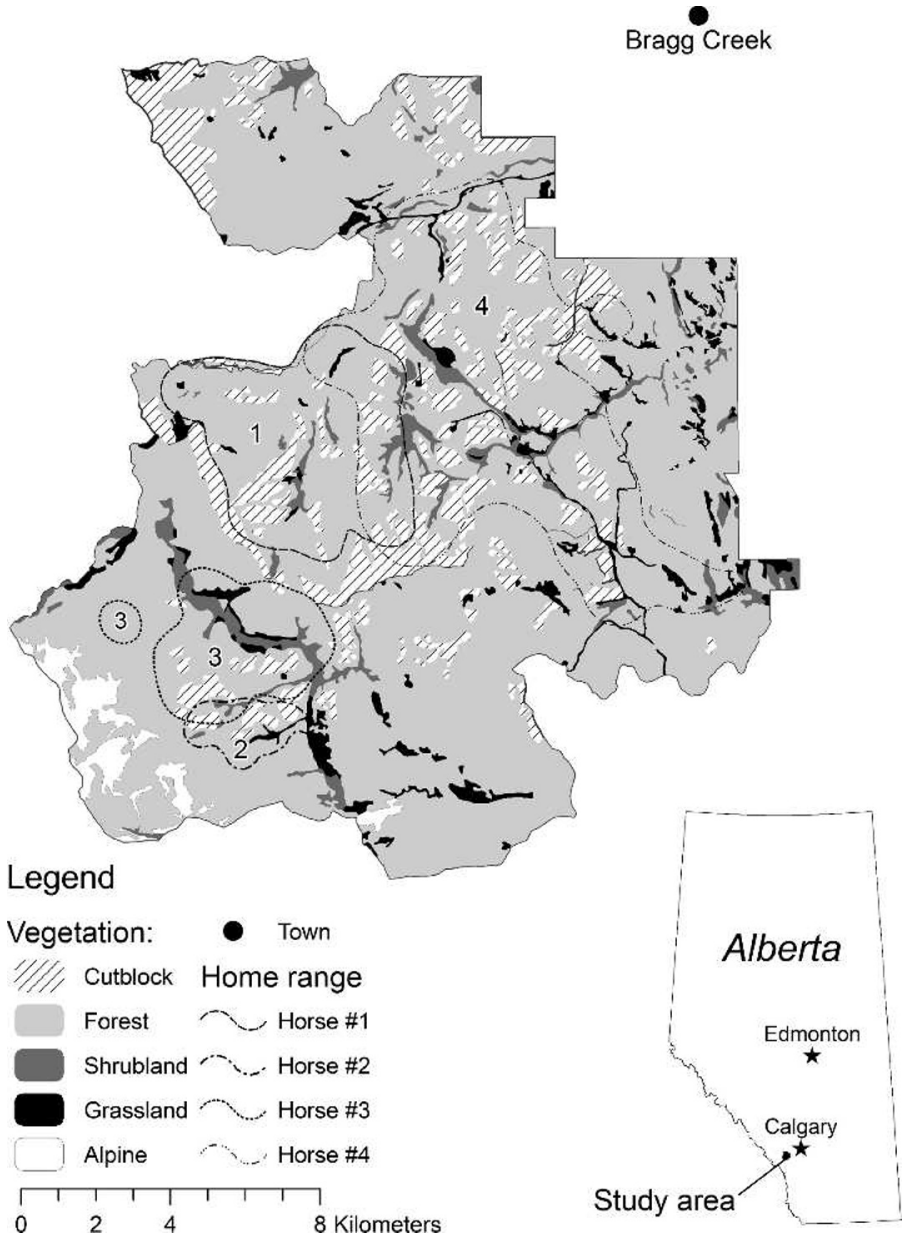

Figure 1. Distribution of vegetation types within the study area and associated home ranges of the four horses studied, within the Rocky Mountain Natural Region of southwest Alberta, Canada.

lands $>$ conifer cutblocks $>$ mixedwood forests $>$ conifer forests (ASRD 2005).

Weather varies greatly among seasons, with daily mean temperatures at the nearby Elbow Ranger Station ranging from $-9^{\circ} \mathrm{C}$ in January to $12^{\circ} \mathrm{C}$ in July and August (Environment Canada 2010). Mean annual precipitation for the area is 644 $\mathrm{mm}$, with most falling as rain between 1 May and 31 August. Annual precipitation for both years of the study remained near normal, although seasonal patterns of precipitation differed between years (Fig. 2).

\section{Habitat Use by Horses}

Approximately 131 feral horses, distributed among 11 harems, are found in the study area. Four randomly selected mares from four different harems were tranquilized from a helicopter and fitted with GPS collars by Alberta Environment and Sustainable Resource Development (AESRD) staff under supervision of a practicing veterinarian in October of 2008. Horses ranged from 3 to $7 \mathrm{yr}$ in age, were of a medium frame size (approximately 12.2 to 14.2 hands high), and were healthy and representative of the majority of mares in the herd. Three of the four mares were pregnant at the time of collaring. Harem sizes ranged from 9 to 27 in size at the time of collaring. Only mares were collared as they are less likely to be involved in dominance 


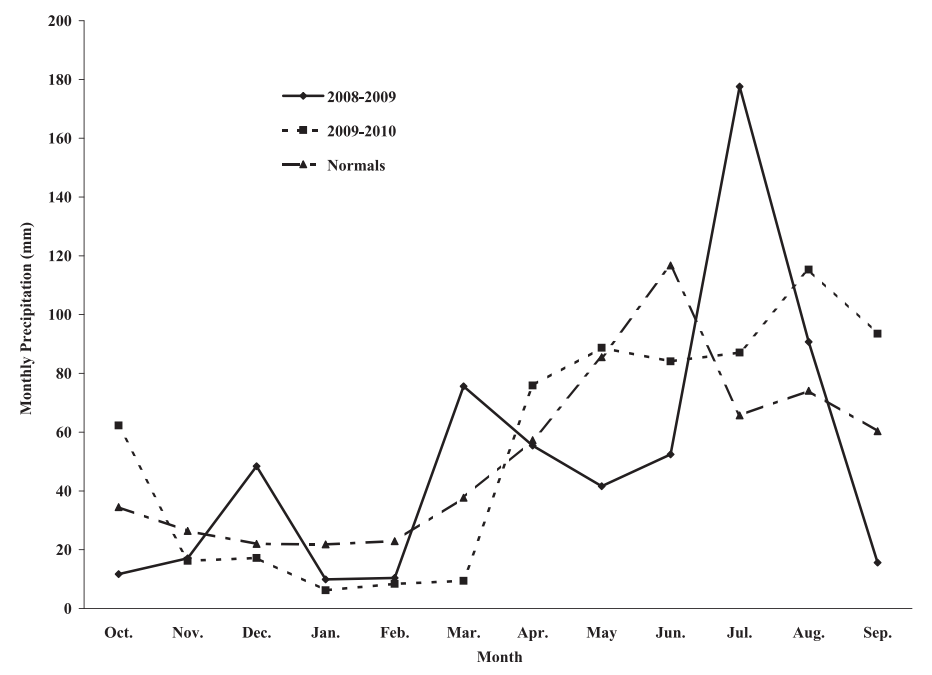

Figure 2. Actual (2009 and 2010) and long-term (30-yr) mean monthly precipitation for the study area according to the Elbow River Ranger Weather Station.

fighting and are more likely than stallions to remain within the same harem.

Lotek 7000 series GPS collars were programmed to record GPS locations once every hour for a 2-yr period between 28 October 2008 and 8 October 2010 for one mare, and until 25 October 2010 for the remaining three mares. Collars recorded the date and time, location (elevation, latitude, and longitude), dilution of precision (DOP), ambient temperature, number of satellites used to obtain a fix, viability of the fix, and the type of fix (2D or 3D; Lotek Wireless Inc. 2011). No problems were encountered with the collars, and data were remotely downloaded every 6 mo. Collars weighed approximately 1.25 $\mathrm{kg}$ and did not appear to interfere with routine horse behavior.

Data on feral horse locations were entered into a geographic information system (GIS) using ArcGIS 9.3 (ESRI 2009) and converted to Universal Transverse Mercator format. Datasets were initially screened for errors caused by obvious incorrect fixes (i.e., points outside the study area) or high DOP $(>6)$, leading to the removal of $9.6 \%$ of observations because they were considered inaccurate (D'Eon et al. 2002). Conifer forests were most likely to experience poor satellite reception due to interference with tall trees (Rempel and Rodgers 1997; Dussault et al. 1999).

\section{Landscape Factors of Habitat Selection}

Spatial databases describing different landscape features for the study area (Table 1) were obtained from provincial digital data archives (AESRD). Vegetation types were defined by the Alberta Vegetation Inventory (AVI), which is based on photointerpreted vector polygons of uniform vegetation age, structure, and composition. AVI maps were grouped into the following five broad categories for electivity analyses of vegetation selection: conifer forest, conifer cutblocks, mixedwood forests, grasslands, and riparian shrublands.

For the subsequent analysis investigating both categorical and continuous factors influencing habitat selection, conifer and mixedwood forest were assessed both individually and together in a single combined "forest" variable. In addition, a topographic ruggedness index (TRI) and an index of solar radiation exposure were estimated for the study area using a 25-m digital elevation model. TRI was estimated using an ArcScript by Riley et al. (1999) that assesses changes in elevation between adjacent grid $(25 \mathrm{~m})$ cells. Solar radiation exposure was calculated for both diffuse and global solar radiation for the first official day of spring (21 March) using an ArcScript based on the equations from Kumar et al. (1997). Finally, the "near" function in ArcMap 9.3 was used to generate distances between horse locations and the various landscape features, including forest cover, water, and roads or trails.

\section{Home Ranges and Sampling of Habitat Availability}

Home ranges are areas where animals perform normal activities and spend the majority of their time (Burt 1943). Home ranges were created for each collared horse to determine the availability of habitat and landscape features. As home ranges showed little interannual variation, a single home range was developed for each animal for the entire study period (Fig. 1). Home ranges from different animals were independent based on visual assessment, as home ranges typically followed watershed boundaries. Moreover, collared horses were never found together during the study, with limited overlap in home ranges (Fig. 1), suggesting collared horses and their associated harems remained independent.

To define home ranges, we used kernel density methods, a nonparametric statistical approach for estimating probability densities from a set of locational points (Rodgers and Kie 2010). Kernel home ranges were created using the Home Range Tools developed by Rodgers et al. (2007) in ArcMap 9.3.1 (ESRI 2009). As recommended by Blundell et al. (2001), fixed kernel distributions with the reference bandwidth were used to develop home ranges with 95\% use polygons. A 95\% kernel home range was used for all analyses to account for the majority of horse activities. Since there was a 1-hr time lag between successive GPS location points, spatial autocorrelation was likely present in the data. However, work done by de Solla et al. (1999) found that an increased number of data points improved spatial accuracy and precision; therefore, the entire corrected data set was used to ensure robust home range development.

Random points were generated at a density of one location per hectare to estimate the availability of habitats for each horse. Random locations were assessed for the same landscape features as horse locations, thereby allowing comparison of used and available spatial data for each horse.

\section{Habitat Electivity and Resource Selection Function Analysis}

Resource selection functions (RSFs) quantify how animals select areas of the landscape (Manly et al. 2002). We used a type III study design (Manly et al. 2002) where selection of used vs. available resources was assessed specific to each horse. Used resources were defined seasonally from horse location information (i.e., the proportion of total observations within each habitat), while available resources were generated for each horse within individual home ranges.

Vegetation use data (i.e., horse point locations) were compared with vegetation type availability (i.e., random 
Table 1. Description of habitat themes and associated variables developed in ArcGIS 9.3 for use in the assessment of feral horse resource selection.

\begin{tabular}{|c|c|c|}
\hline Theme $^{1}$ & Variable & Description \\
\hline Vegetation & Avoided & Habitat polygon with electivity $<0.1=$ use, $0=$ nonuse \\
\hline \multirow[t]{2}{*}{ Type } & Neutral & Habitat polygon with electivity not different from $0.1=$ use, $0=$ nonuse \\
\hline & Selected & Habitat polygon with electivity $>0.1=$ use, $0=$ nonuse \\
\hline Water and & D. water & Distance from horse/random points to nearest source of water (100 m) \\
\hline Topography & Elevation ${ }^{2}$ & Elevation above sea level ranging from 1341 to $2330 \mathrm{~m}$ \\
\hline Access and & D. roads/trails & Distance from horse/random points to nearest road or trail (100 m) \\
\hline Disturbance & D. seismic lines & Distance from horse/random points to the nearest cutline $(100 \mathrm{~m})$ \\
\hline \multirow[t]{6}{*}{ Thermal } & D. mixedwood & Distance from horse/random points to the nearest mixedwood forest (100 m) \\
\hline & D. conifer & Distance from horses/random data points to the nearest conifer forest $(100 \mathrm{~m})$ \\
\hline & D. any forest & Distance from horses/random data points to nearest forest $(100 \mathrm{~m})$ \\
\hline & $\mathrm{TR}^{2,3}$ & Terrain ruggedness index, increasing values indicate increasing roughness \\
\hline & $\mathrm{DSR}^{2}$ & Diffuse solar radiation. Measure of scattered wavelengths on March 21 \\
\hline & $\mathrm{GSR}^{2}$ & Global solar radiation. Measure of shortwave + diffuse radiation \\
\hline \multirow[t]{3}{*}{ Interactions } & D. water $\times$ TRI & Combination of distance to water and ruggedness \\
\hline & D. water $\times$ elevation & Combination of distance to water and elevation \\
\hline & TRI $\times$ elevation & Combination of elevation and ruggedness \\
\hline
\end{tabular}

${ }^{1}$ See text for a detailed explanation of themes and associated variables.

${ }^{2}$ Indicates raster data.

${ }^{3} \mathrm{TRI}$ indicates topographic ruggedness index; DSR, diffuse solar radiation; GSR, global solar radiation.

points) using Ivlev's Electivity Index (EI; Ivlev 1961; see Equation 1) to determine horse selection for each vegetation type.

$$
\begin{aligned}
E I_{\text {veg type "x" }}= & (\% \text { horse use in "x" }-\% \text { of " } x " \text { available }) / \\
& (\% \text { horse use in " } x "+\% \text { of " } x " \text { available })
\end{aligned}
$$

Electivity data indicated those vegetation types that were selected $(\mathrm{EI}>0)$, avoided $(\mathrm{EI}<0)$, or neutral (i.e., habitat was occupied in the same proportion as available on the landscape; $\mathrm{EI}=0$ ). Electivities were calculated separately for each horse, and examined for year, season, and time of day effects. Differences in electivity among vegetation types were then tested in SAS 9.2 with the residual maximum likelihood method, incorporating individual horse as a random effect (Gillies et al. 2006).

Following the electivity analyses of vegetation types, RSF analyses (i.e., information theoretics) were used to evaluate the relative influence of both categorical and continuous landscape features on horse habitat selection. Separate RSFs were developed for winter, spring, summer, and fall seasons over both years, as preliminary analysis of the habitat data revealed marked differences in electivity between seasons, but not years. Cut-off dates between seasons were established from combinations of expected changes in plant growth and associated forage availability based on known changes in plant phenology, snow cover, etc. Using these criteria, the winter season was defined as 1 November to 31 March and coincided with the period of snow cover. Spring was from 1 April to 15 May, representing the short transition from vegetation dormancy through initial green-up. Summer was defined as 16 May to 15 September, and included the growing season and period of greatest herbage production and forage availability. Finally, fall was defined as 16 September to 31 October, coincident with rapid plant senescence before snow fall reduces forage accessibility. Analysis comparing horse distributions between day and night revealed no clear diurnal patterns; thus, no further division based on time of day was considered.

In preparation for the RSF analysis, used and available spatial locations, along with all vegetation type and other habitat (i.e., landscape) variables, were combined to create a dataset for each horse. Used data points were set to " 1 ," while those available were set to "0." Variables used for resource selection (see Table 1) were initially examined for redundancy using Pearson's correlations with Proc CORR in SAS 9.2. Variables correlated at $r>0.7$ across all horses were considered redundant and removed, leaving one variable per group. However, variables were retained when at least one animal did not exhibit correlation prior to data combination. The diffuse solar radiation and elevation by ruggedness interaction were both correlated with ruggedness. Ruggedness was retained because it was considered representative of many environmental variables. Similarly, the distance to water by elevation interaction was correlated with distance to water, with the latter retained because of its ease of measurement and interpretation.

As a first step in the RSF, variables were divided into themes representing different a priori hypothesized factors influencing use patterns by feral horses (Table 1), which reduced the number of variables for final comparison in a hierarchical manner. To determine the most representative variables from each theme the $-2 \log$ likelihood (-2LL) was obtained using Laplace Approximation with horse as a random effect in Proc GLIMMIX in SAS 9.2 (Gillies et al. 2006). The-2LL was used to generate a pseudo $R^{2}$ (goodness-of-fit) for each model to compare the percentage of deviance explained by all models in comparison to the null (Windmeijer 1995; Cameron and Windmeijer 1997; see Equation [2]).

McFadden's pseudo $R^{2}=1-(\log$ likelihood candidate model/ log likelihood null model)

Within each theme, the model that best explained deviance in horse use was selected. Usually this was the model with the 
Table 2. Mean electivity for various vegetation types by feral horses in the Rocky Mountain Forest Reserve of Alberta from October 2008 through 0ctober 2010. Electivities with a * indicate those that horses either preferred $(>0)$ or avoided $(<0)$, at $P<0.05$. Pooled standard error \pm 0.15 across all treatments.

\begin{tabular}{lcccc}
\hline Vegetation type & Winter (1 November-March 31) & Spring (1 April-May 15) & Summer (16 May-September 15) & Fall (16 September-31 October) \\
\hline Conifer & $-0.444^{\star} \mathrm{AB}^{1} \mathrm{c}^{2}$ & $-0.618^{*} \mathrm{~B} \mathrm{C}$ & $-0.300^{\star} \mathrm{A} \mathrm{C}$ & $-0.19^{*} \mathrm{~A} \mathrm{~b}$ \\
Cutblock & $0.328^{\star} \mathrm{A} \mathrm{a}$ & $-0.102 \mathrm{~B} \mathrm{~b}$ & $0.046 \mathrm{AB} \mathrm{b}$ & $0.073 \mathrm{AB}$ ab \\
Grassland & $0.506^{\star} \mathrm{A} \mathrm{a}$ & $0.718^{\star} \mathrm{A} \mathrm{a}$ & $0.602^{\star} \mathrm{A} \mathrm{a}$ & $0.226^{\star} \mathrm{B} \mathrm{a}$ \\
Mixedwood & $-0.053 \mathrm{~A} \mathrm{~b}$ & $0.190^{\star} \mathrm{A} \mathrm{b}$ & $0.013 \mathrm{~A} \mathrm{bc}$ & $-0.046 \mathrm{~A}$ ab \\
Shrubland & $-0.005 \mathrm{~A} \mathrm{~b}$ & $0.195^{\star} \mathrm{A} \mathrm{b}$ & $0.192^{\star} \mathrm{A} \mathrm{b}$ & $-0.096 \mathrm{Ab}$
\end{tabular}

${ }^{1}$ Seasonal means within a row with different uppercase letters differ, $P<0.05$.

${ }^{2}$ Vegetation type means within a column with different lowercase letters differ, $P<0.05$.

greatest percent deviance explained, with the condition that increasing the number of variables required an increase of at least $1 \%$ deviance per variable. Where no model had an explanatory power greater than $1 \%$, the best model was chosen to move forward to represent that theme in the final model testing. Model selection was completed separately for each season. Finally, additional models were created treating avoided, neutral, or selected (ANS) vegetation types (i.e., core selection) as a null model following the same process outlined above.

Once the best model from each theme was identified, these models were combined in an additive fashion and run through Proc GLIMMIX to determine the final model that best accounted for overall patterns of horse selection. The first model used the theme with the greatest explanatory value from the previous stage. Themes were added and tested in descending fashion, and carried forward to the next test provided they yielded a $1 \%$ increase in pseudo $R^{2}$. This was done for each season to generate the final models and variables for inclusion in the RSFs. Final RSFs (Manly et al. 2002) were developed to describe the relationships between horses and various significant landscape characteristics (see Equation [3]).

$$
R S F=\exp \left(\beta_{1} x_{1}+\ldots+\beta_{p} x_{p}\right)
$$

Finally, beta $(\beta)$ coefficients were obtained from the Proc GLIMMIX (SAS Institute 2007) output used to produce the $-2 \mathrm{LL}$, and the RSFs used to predict habitat selection across the study area representing the likelihood of horse presence for each season. This was done using the Map Algebra function in ArcMap 9.3 where the betas from the logistic model were used to predict local habitat selection based on landscape values for each $25-\mathrm{m}$ pixel.

\section{RESULTS}

\section{Home Ranges and Vegetation Electivity}

Kernel home range analysis indicated that horses occupied different areas of the study area and had varying home range size. The $95 \%$ kernel home ranges of the four horses ranged from 12.4 to $90.0 \mathrm{~km}^{2}$ (mean $=48.4 \mathrm{~km}^{2}$ ). Home range sizes closely followed individual watershed boundaries, rarely extending into adjacent watersheds, but were also highly correlated with the initial size of harems for each collared horse $(r=0.97)$.
Horse electivity for different vegetation types varied within individual seasons (Table 2). In winter, horses selected conifer cutblocks and grasslands $(P<0.05)$. In spring, lowland grasslands, mixedwood forests, and riparian shrublands were selected, a pattern that continued through summer for the two nonforested habitats. During fall, horses selected lowland grasslands and exhibited similar electivity for cutblocks.

Selection of individual vegetation types by horses also varied seasonally (Table 2). For example, grasslands were strongly selected in every season but remained lower during fall than at other times of the year $(P<0.05)$. Riparian shrublands were selected in spring and summer. Although conifer forests were avoided in all seasons, this habitat was avoided most during spring. Selection for cutblocks occurred only in winter, with this vegetation type being neutral in all other seasons. A similar pattern was evident for mixedwood forests with selection only in spring.

\section{Resource Selection Functions}

Comparison of the a priori models within individual themes indicated that the same variables or variable combinations explained the majority of deviance in horse presence across the study area during winter, spring, and summer (Table 3). The core ANS model, representing the vegetation theme, was carried forward to all RSF models as it represented our null model of general selection for vegetation types. For the water and topography theme, ruggedness was selected as the most important factor. Within the disturbance theme, distance to roads and trails was selected as the most important factor although it explained little variation $(<1 \%)$ in habitat selection. The model that explained the most deviance in the thermal theme was distance to both forest types (mixedwood and conifer), in combination with solar radiation. This model also explained more deviation in horse selection than all other themes (Table 3). Comparative models between seasons were generally consistent in variable selection within themes, with one notable exception: within the disturbance theme, the fall model with roads and trails in combination with seismic lines explained more deviance than roads and trails alone (Table 3). When ranking individual themes (hypothesized factors) their order of importance was: thermal $>$ habitat $>$ water and topography $>$ disturbance. This ranking was consistent across all seasons.

In the final analysis (i.e., model combination across themes) of winter horse data, the model that explained the most deviance was the "thermal+habitat" model at $21.3 \%$ (Table 4). 
Table 3. Summary results depicting comparative model strength linking feral horse observations from global positioning system telemetry data collected during winter (1 November-31 March), spring (1 April-15 May), summer (16 May-15 September), and fall (16 September-31 October) 2009 and 2010 , and various landscape attributes. Bolded and italicized components indicate the leading model in a theme, and which were carried forward into the final assessment.

\begin{tabular}{|c|c|c|c|c|c|c|}
\hline \multirow[b]{2}{*}{ Theme } & \multirow[b]{2}{*}{ Component } & \multirow[b]{2}{*}{$\mathrm{K}^{1}$} & \multicolumn{4}{|c|}{$R^{2}$} \\
\hline & & & Winter & Spring & Summer & Fall \\
\hline Null & & 1 & $0.00^{2}$ & 0.00 & 0.00 & 0.00 \\
\hline Vegetation type & ANS $^{3}$ & 3 & 11.19 & 17.18 & 7.92 & 3.19 \\
\hline \multirow[t]{5}{*}{ Water and topography } & D. water & 2 & 0.01 & 0.69 & 0.00 & 0.03 \\
\hline & TRI & 2 & 3.55 & 1.35 & 3.45 & 1.77 \\
\hline & D. water $\times$ TRI & 2 & 0.68 & 1.22 & 0.89 & 0.18 \\
\hline & D. water + TRI & 3 & 3.57 & 2.06 & 3.45 & 1.79 \\
\hline & D. water $+\mathrm{TRI}+\mathrm{D}$. water $\times \mathrm{TRI}$ & 4 & 3.92 & 2.15 & 3.69 & 2.35 \\
\hline \multirow[t]{3}{*}{ Disturbance } & D. roads/trails & 2 & 0.25 & 1.12 & 0.91 & 0.42 \\
\hline & D. seismic lines & 2 & 0.01 & 0.33 & 0.08 & 0.88 \\
\hline & D. roads/trails + D. seismic line & 3 & 0.29 & 1.27 & 0.94 & 1.18 \\
\hline \multirow[t]{9}{*}{ Thermal } & D. any forest & 2 & 5.90 & 6.31 & 3.84 & 1.67 \\
\hline & D. conifer & 2 & 3.12 & 3.52 & 2.10 & 1.16 \\
\hline & D. mixedwood & 2 & 7.01 & 7.25 & 7.83 & 6.41 \\
\hline & GSR & 2 & 3.31 & 6.87 & 2.05 & 1.36 \\
\hline & D. conifer + D. mixedwood & 3 & 11.77 & 12.92 & 11.94 & 8.94 \\
\hline & D. conifer + GSR & 3 & 6.30 & 10.70 & 4.03 & 2.49 \\
\hline & D. mixedwood + GSR & 3 & 9.89 & 13.24 & 9.67 & 7.53 \\
\hline & D. any forest + GSR & 3 & 9.04 & 13.49 & 5.79 & 2.99 \\
\hline & D. mixedwood + D. conifer + GSR & 4 & 14.44 & 19.30 & 13.62 & 10.03 \\
\hline
\end{tabular}

${ }^{1}$ Indicates the number of parameters used.

${ }^{2}$ McFadden's pseudo $R^{2}$ goodness-of-fit measure.

${ }^{3}$ ANS indicates avoided, neutral, or selected; TRI, topographic ruggedness index; GSR, global solar radiation.

Variables included in the final winter model were distance to conifer and distance to mixedwood forests (i.e., uncombined), solar radiation, and vegetation type (ANS) selection. In the final spring analysis, the leading model was "thermal+habitat+disturbance," explaining $31.5 \%$ of deviation in horse distribution (Table 4). Variables included in the spring model were the same as winter, with the addition of distance to roads and trails. During final analysis of the summer horse habitat selection, the leading model was "thermal + habitat," explaining $17.2 \%$ of horse distribution (Table 4), and included the same variables as the winter model. The most appropriate fall model was the "thermal+habitat + disturbance" combination, explaining a relatively low amount of variance at $13.3 \%$ (Table 4). This model had the same variables as the spring model, with the addition of distance to seismic lines.

A similar type of relationship existed for thermal and habitat variables regardless of season. Habitat selection was positively related to distance to conifer and mixedwood forests and solar radiation (Table 5). During spring and fall, habitat selection increased with distance to roads/trails and seismic lines (Table $5)$.

Table 4. Final summary results depicting comparative model strength of combined themes of feral horse observations from global positioning system telemetry data collected during winter (1 November-31 March), spring (1 April-15 May), summer (16 May-15 September), and fall (16 September-31 October) of 2009 and 2010, and various landscape attributes. Bolded and italicized model indicates final model selection.

\begin{tabular}{|c|c|c|c|c|c|c|}
\hline \multirow[b]{2}{*}{ Theme } & \multirow[b]{2}{*}{ Component (Final spring analysis) ${ }^{1}$} & \multirow[b]{2}{*}{$\mathrm{K}^{2}$} & \multicolumn{4}{|c|}{$R^{2}$} \\
\hline & & & Winter & Spring & Summer & Fall \\
\hline Null & & 1 & $0.00^{3}$ & 0.00 & 0.00 & 0.00 \\
\hline Thermal & D. conifer + D. mixedwood + GSR $^{4}$ & 4 & 14.44 & 19.30 & 13.62 & 10.03 \\
\hline Thermal + Vegetation Type & D. conifer + D. mixedwood + GSR + ANS & 6 & 21.25 & 30.28 & 17.15 & 11.47 \\
\hline Thermal + Veg Type + Water and Access & D. conifer + D. mixedwood + GSR + ANS + TRI & 8 & 22.02 & 30.29 & 17.61 & 11.79 \\
\hline Thermal + Veg Type + Disturbance & D. conifer + D. mixedwood + GSR + ANS + D. roads $/$ trails $^{5}$ & 8 & 21.74 & 31.48 & 17.76 & 13.26 \\
\hline Thermal + Veg Type + Water and Access + Disturbance & D. conifer + D. mixedwood + GSR + ANS + TRI + D. roads/trails & 9 & 22.70 & 31.56 & 18.45 & 14.12 \\
\hline
\end{tabular}

\footnotetext{
${ }^{1}$ Component terms are defined in Table 1.

${ }^{2}$ Indicates the number of parameters used.

${ }^{3}$ McFadden's pseudo $R^{2}$ goodness of fit measure.

${ }^{4}$ ANS indicates avoided, neutral, or selected; TRI, topographic ruggedness index; GSR, global solar radiation.

${ }^{5}$ For the fall, disturbance consisted of D. roads/trails and D. seismic lines.
} 
Table 5. Ranked influence of different variables in the leading resource selection function models by season of use for feral horses in the Alberta foothills. Data based on observations collected between October 2008 and October 2010.

\begin{tabular}{|c|c|c|}
\hline Variable & $\beta^{1,2}$ & $\mathrm{SE}^{3}$ \\
\hline \multicolumn{3}{|c|}{ Winter (1 November-31 March) } \\
\hline D. conifer & 0.380 & 0.001 \\
\hline D. mixedwood & 0.076 & 0.021 \\
\hline $\mathrm{GSR}^{4}$ & 0.200 & 0.000 \\
\hline Selected & 0.580 & 0.031 \\
\hline Avoided & -1.140 & 0.033 \\
\hline \multicolumn{3}{|l|}{ Spring (1 April-15 May) } \\
\hline D. conifer & 0.250 & 0.002 \\
\hline D. mixedwood forest & 0.088 & 0.032 \\
\hline $\mathrm{GSR}^{4}$ & 0.340 & 0.000 \\
\hline Selected & 0.980 & 0.045 \\
\hline Avoided & -0.62 & 0.054 \\
\hline D. roads and trails & 0.067 & 0.004 \\
\hline \multicolumn{3}{|c|}{ Summer (16 May-15 September) } \\
\hline D. conifer & 0.560 & 0.001 \\
\hline D. mixedwood forest & 0.077 & 0.022 \\
\hline $\mathrm{GSR}^{4}$ & 0.140 & 0.000 \\
\hline Selected & 1.030 & 0.035 \\
\hline Avoided & -0.310 & 0.031 \\
\hline \multicolumn{3}{|c|}{ Fall (16 September-31 October) } \\
\hline D. conifer & 0.450 & 0.031 \\
\hline D. mixedwood & 0.074 & 0.002 \\
\hline $\mathrm{GSR}^{4}$ & 0.110 & 0.00 \\
\hline Selected & 0.850 & 0.066 \\
\hline Avoided & -0.560 & 0.430 \\
\hline D. roads and trails & 0.031 & 0.0033 \\
\hline D. seismic lines & 0.110 & 0.006 \\
\hline
\end{tabular}

${ }^{1}$ Beta coefficient.

${ }^{2}$ All $\beta$ coefficients shown have a significance of $P<0.0001$.

${ }^{3}$ Standard error.

${ }^{4}$ GSR values are $\times 10^{-3}$; GSR, global solar radiation.

Final RSF maps created for each season (Fig. 3) reflected the likelihood of habitat selection by horses based on different aggregate habitat conditions (vegetation types, terrain, and distances to disturbances) across the study area. Seasonal RSF maps were scaled in ArcGIS 9.3 to seven ordinal ranked categories of selection using quantile binning. Seasonal habitat suitability maps indicated that $14 \%$ of the landscape was selected, $42 \%$ of the landscape was avoided, while the remainder of the study area was neutral (i.e., used according to availability).

\section{DISCUSSION}

\section{Home Ranges of Feral Horses}

Previous work has shown that horse home ranges can vary considerably in size (McCort 1984), consistent with our findings. The average home range of horses examined here was $48 \mathrm{~km}^{2}$, which was $33 \mathrm{~km}^{2}$ larger than that found by Salter and Hudson (1982) within a similar environment in west central Alberta. Interpretation of our home ranges should be

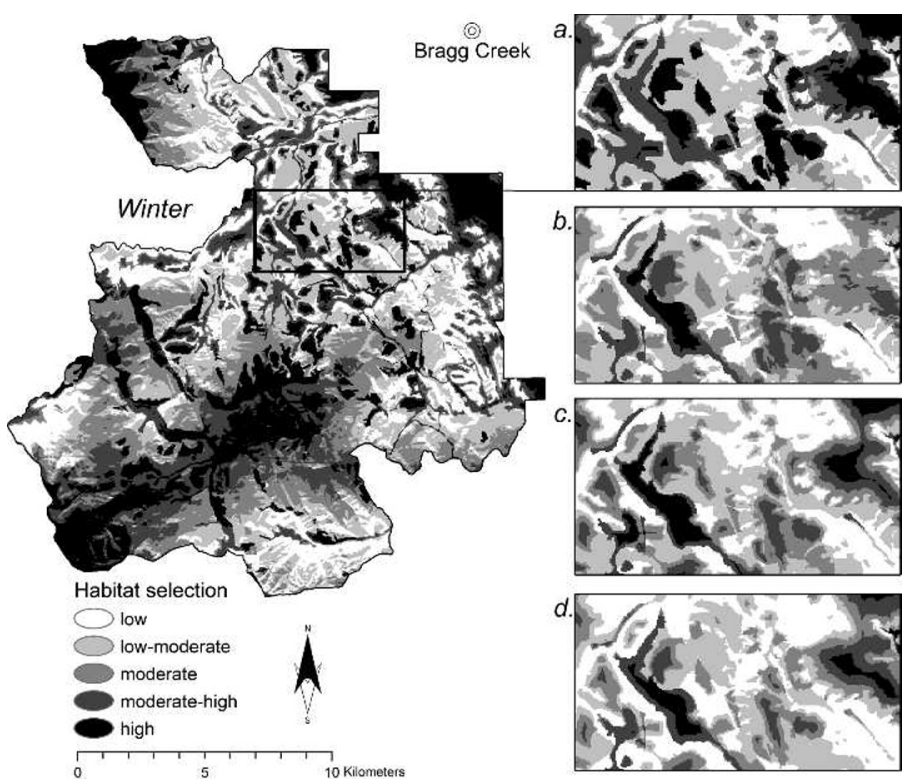

Figure 3. Maps depicting the likelihood of horse use for feral horses in the McLean Creek area of southwest Alberta, based on resource selection functions (RSFs) developed for the region. Subset maps represent the a) winter, b) spring, c) summer, and d) fall seasons.

tempered by the $95 \%$ kernel ranges we used and risk of correlation among horses, which is known to underestimate home range size (Peridotto-Baldivieso 2012). Should this be the case, however, sampled horses would have even larger home ranges, further differentiating them from Salter and Hudson (1982). Although the larger home ranges in the current study could arise because of a difference in resource availability or exposure to disturbances between study areas, differences in study methodology (i.e., use of GPS collars here) may also influence home range size. The ability of GPS collars to continuously track horse movement throughout the year would effectively maximize home ranges. In contrast, Salter and Hudson (1982) relied on field observations, which occurred under a limited sampling period and intensity, and may have underestimated home range size.

The relatively stable home ranges across consecutive seasons suggested that these animals had territorial and home range fidelity, similar to the findings of Ganskopp and Vavra (1986). As feral horses are gregarious animals (McCort 1984), it is likely that home ranges mapped in the current study are representative of harems rather than individual animals. Although some horses appeared to use habitats at a greater intensity than others based on our data (i.e., horse 2, which had a very small home range), this was not supported by the strong association between initial harem sizes and home ranges. High variation in landscape diversity also ensured that each horse had access to all habitats, even within a relatively small area. Moreover, horse 2 occupied the most isolated (and least accessible) region, which may have led to a reduction in human disturbance. In contrast, harems situated closer to increased human activity (i.e., near public campgrounds) had larger home ranges. Larger home ranges in these areas could arise as horses move about to avoid interactions with humans (Laliberte and Ripple 2004), a finding supported by the RSF models from 
spring and fall when disturbances were relatively more important (Table 5). However, the large home range size of the collared horse nearest the campground (horse 4 in Fig. 1) may also have occurred because resources were more limited in this high traffic area. This region had the smallest proportion of (preferred) grasslands and shrublands of all home ranges.

\section{Seasonal Selection by Horses}

Distinct seasonal trends in habitat selection were observed, particularly for vegetation types. During summer, horses strongly selected for grasslands and riparian shrublands. Both these habitats have favorable herbage production (ASRD 2005), as well as the grasses and sedges specifically sought out by horses when foraging (Salter and Hudson 1979). Preferred species during summer and commonly found in grasslands and shrublands included Deschampsia caespitosa, Festuca spp., Poa spp., Carex spp., and Phleum pratense. Although depletion of forage could arise at this time of year given that cattle are using similar vegetation types as horses (Girard et al. 2013) and have similar diets to horses (McInnis and Vavra 1987), interspecific competition is unlikely during this time given the rapid growth and biomass increases observed, with maximum production values for grasslands ranging from $3600 \mathrm{~kg} \cdot \mathrm{ha}^{-1}$ to $4000 \mathrm{~kg} \cdot \mathrm{ha}^{-1}$ in this region (ASRD 2005; Girard et al. 2013).

During fall, horses selected grasslands, but at a lower level than during summer, and avoided conifer forest, with all other vegetation types used according to availability. Reduced selection for grasslands during fall may be due to progressive depletion of available forage in habitats selected during summer by the combined grazing pressure from feral horses and domestic cattle (Girard et al. 2013). This in turn may account for the increased habitat selection for cutblocks during fall and winter, particularly given that horses are known to prefer high biomass areas (Fleurance et al. 2009).

Increased selection by horses for conifer cutblocks during winter contradicts Irving (2001) who found horses in the Upper Foothills of Alberta (350 km NW of this study) selected disturbed areas (e.g., roadsides, pipelines, and other developed lands) over pine cutblocks. The increase in selection for conifer cutblocks found here may be a strategy by horses to widen their search for remaining forage (Salter and Hudson 1979), particularly with depletion of forage within their primary grassland ranges. Similar to feral horses in the current study, cattle in Alberta avoided conifer cutblocks during summer (Kaufmann 2011). In combination, these results suggest forage in conifer cutblocks is less likely to be as depleted as other habitats (grasslands and riparian shrublands) by early winter. Finally, harvested conifer cutblocks that occur above the valley bottom are less susceptible to cold air drainage during winter (Henson 1952), and therefore have warmer conditions compared with valley bottom grasslands. Ambient temperatures from the GPS collars support this as mean temperatures during January were $4^{\circ} \mathrm{C}$ greater for horses occupying conifer cutblocks than those in lowland grasslands.

Increased selection for shrublands during spring coincides with the increased presence of shrubs in the spring diets of horses observed (based on fecal assessment) by Salter and Hudson (1979). Increased use of shrublands may arise because of a greater ability by horses to access these areas as snow melts, coupled with taller shrubs representing some of the only forage available after winter and prior to spring green up. This notion is also supported by the observation that the greatest aversion to conifer forests was evident during spring wherein snow is likely to persist. Overall, our findings suggest feral horses may be adapting seasonally to utilize what forage is available, accessible, and of suitable quality within their home ranges. This includes shifts throughout the year in the identity of primary habitat (i.e., vegetation) types.

\section{Mechanisms Regulating Habitat Selection by Horses}

Although habitat selection by feral horses differed by season, several common trends were evident. For all seasons, thermal aspects, in addition to core vegetation type, were important predictors of selection. Feral horses selected open areas away from conifer and mixedwood forests. Although forests may be used for temperature regulation by providing shade in summer and relief from wind and cold during winter (Musterud and Østbye 1999), our results indicated horses were not utilizing forest cover as expected. Instead, selection for the combined factors of solar radiation and greater distance from forested areas suggests horses may have been maximizing sun exposure, which would aid in winter thermoregulation. Similar observations have been made with cattle in Montana during winter (Keren and Olson 2007). Conversely, sun exposure may not have been high enough for horses to seek thermal cover during summer, and relatively cool summer temperatures in this environment (generally $<30^{\circ} \mathrm{C}$ ) may have limited the need for horses to seek shade. Forests also contain relatively low amounts of forage (Girard et al. 2013), which may dissuade horses from using these areas, at least when foraging. Finally, forests may be associated with greater exposure to predation. Horses are thought to be susceptible to predation, particularly from cougars (Puma concolor; Knopff 2010), and avoidance of forests may be an adaptive strategy to minimize this risk. Despite this risk, comparison of habitat selection in cutblock core and perimeter areas revealed horses did not exhibit differential use between these zones (data not shown).

Aversion by horses to roads, trails, and seismic lines may occur because of the large amount of human activity on and near these features (Laliberte and Ripple 2004). Roads and trails are traveled extensively by recreationalists, including hikers, cyclists, dirt bikers, off-highway vehicle riders, snowmobilers, and horseback riders. While this aversion was expected to be more prevalent in summer (i.e., during peak recreation use) than fall or spring, the opposite pattern was observed. Horses may be avoiding linear features during the transitional seasons due to a reduction in concealment cover. Areas adjacent to trails are where the majority of deciduous woody species (shrubs and trees) are found, and spring and fall would coincide with periods prior to leaf-out and after leaf-fall, respectively. Although we hypothesized that horses could be using linear features as movement corridors, this did not occur. Horses may also avoid linear features because the latter can attract predators (Whittington et al. 2005). Caution should be exercised in interpreting horse selection patterns during the short, transitional spring and fall seasons, as a smaller sample size of observations could result in less robust RSF models, and 
more variability may be expected in horse use within these seasons from year to year.

Water and topography did not affect habitat selection by horses, regardless of season. The lack of a water association corroborates Salter and Hudson (1979) who concluded that water was not limiting for horses in the Alberta foothills. Moreover, the finding that ruggedness was not a factor influencing habitat selection suggests topography (i.e., elevation, slope, and aspect) does not pose the same limitation for horses as it does for cattle (Kauffman 2011).

Across all seasons, observed RSF models accounted for moderate variation in horse distribution (13.3-31.5\%), and could indicate that other explanatory factors were not captured in our assessment of habitat selection. Model fit was greatest during spring, which was unexpected because spring is one of the shorter and more variable seasons. However, rapidly changing conditions at that time (i.e., coincident with snowmelt and green-up) may have led to more predictable behavior by horses as they attempt to maximize recovery following winter. In contrast, the lowest model fit was during fall, consistent with the notion that this transitional season can bring widely varying foraging conditions depending on the previous summer's growth coupled with variability in the onset of senescence. Finally, we acknowledge the potential limitations imposed by low sample sizes (number of horses) and any interactions among harems across the study area in explaining feral horse use during the 2-yr study period.

\section{MANAGEMENT IMPLICATIONS}

Overall, our results indicate that in southwest Alberta, relatively small amounts of the landscape are preferentially selected by horses, particularly grasslands and shrublands across all seasons, and during winter, harvested conifer forests (cutblocks). In addition to vegetation type, selection by feral horses was influenced by other habitat characteristics, primarily distance to forests and sun exposure. Although horses used all areas of the landscape, selected grassland habitats had the smallest footprint and are likely the most sensitive to human disturbance as horses avoid roads and trails travelled by people. Future increases in recreational activity may continue to shift feral horse selection from conventional primary range (grasslands and shrublands) into alternate habitats, with any displacement posing a threat to horse survival and localized range health. Future monitoring programs to track recreational use may be useful to determine how these changes alter habitat selection by horses. Moreover, this process may be further complicated by ongoing grassland declines due to shrub encroachment (Burkinshaw and Bork 2009). RSFs generated in this study should enable land managers to map existing and additional primary habitats likely to be used by horses, as well as establish seasonal carrying capacities based on temporal changes in horse use. For example, as horses demonstrated the narrowest selectivity for specific habitats during winter, this period could pose the greatest limitation to horse survival. Consequently, winter habitats may be used to establish yearlong carrying capacities of feral horses in the region.

Selection of harvested conifer forests in winter could also be problematic and lead to heightened land use conflict between the forest industry and feral horse management. For example, it is unknown whether, and if so how, increased horse use of conifer cutblocks may change tree seedling damage and regeneration. Similarly, it is unknown whether horse use of cutblocks during winter is influenced by existing levels of grazing from horses, cattle (i.e., during the previous summer), or both, within adjacent primary habitats, or other conditions. High accumulated use of grasslands due to combined horse and cattle grazing (Salter and Hudson 1980; Girard et al. 2013) increases the likelihood of changes to horse behavior. Further study is needed to determine the impact and mechanisms regulating seasonal horse grazing in cutblocks of the region, particularly in conjunction with other land uses.

\section{ACKNOWLEDGMENTS}

We are grateful to Craig DeMaere, Alicia Entem, and Michael Girard for their contributions to the project, and to Drs Robert Hudson, Barry Irving, Simon Landhausser, and Evelyn Merrill, together with two anonymous reviewers, all of whom provided input on an earlier draft of the manuscript.

\section{LITERATURE CITED}

Anderson, D. M. 2010. Geospatial methods and data analysis for assessing distribution of grazing livestock. In: B. W. Hess, T. Delcurto, J. G. P. Bowman, and R. C. Waterman [EDS.]. Proceedings of the 4th Grazing Livestock Nutrition Conference; 9-10 July 2010; Estes Park, CO, USA. Champaign, IL, USA: Western Section American Society of Animal Science. p. 57-92.

[ASRD] Alberta Sustainable Resource Development. 2005. Range plant community types and carrying capacity for the Montane subregion. 6th Approximation. Prepared by M. G. Willoughby, M. J. Alexander, and B. W. Adams. Edmonton, AB, Canada: Public Lands Division, Government of Alberta. Pub. T/071. 248 p.

Balley, D. W., J. E. Gross, E. A. Laca, L. R. Rittenhouse, M. B. Coughenour, D. M. Swift, AND P. L. Sims. 1996. Mechanisms that result in large herbivore grazing distribution patterns. Journal of Range Management 49:386-400.

Blundell, G. M., J. A. K. Maier, And E. M. Debevec. 2001. Linear home ranges: effects of smoothing, sample size, and autocorrelation on kernel estimates. Ecological Monographs 71:469-489.

Bureau of Land Management. 2011. National Wild Horse and Burro Program. US Department of the Interior. Available at: http://www.blm.gov/wo/st/en/prog/ whbprogram.html. Accessed 1 November 2011.

BurkinshaW, A. M., AND E. W. Bork. 2009. Shrub encroachment impacts the potential for multiple use conflicts on public land. Environmental Management 44:493504.

BuRT, W. H. 1943. Territoriality and home range concepts as applied to mammals. Journal of Mammalogy 24:346-352.

Cameron, A. C., and F. A. G. Windmeljer. 1997. An r-squared measure of goodness of fit for some common nonlinear regression models. Journal of Econometrics 77:329-342.

D'Eon, R. G., R. Serrouya, G. Smith, and C. 0. Kochanny. 2002. GPS radiotelemetry error and bias in mountainous terrain. Wildlife Society Bulletin 30:430-439.

De Solla, S. R., R. Bondurianks, and R. J. Brooks. 1999. Eliminating autocorrelation reduces biological relevance of home range estimates. Journal of Animal Ecology 68:221-234

Dussault, C., R. Courtols, J. P. Oullet, and J. Huot. 1999. Evaluation of GPS telemetry collar performance for habitat studies in the boreal forest. Wildlife Society Bulletin 27:965-972.

Environment Canada. 2010. Canadian Climate Normals 1971-2000. Available at: http://www.climate.weatheroffice.gc.ca/climate_normals/results_e. $\mathrm{html}$ ?StnID=2386\&autofwd=1. Accessed 15 October 2010.

ESRI. 2009. Welcome to ArcGIS Desktop 9.3. Available at: http://webhelp.esri.com/ arcgisdesktop/9.3/index.cfm?TopicName=welcome. 
Fleurance, G., H. Fritz, P. Duncan, I. J. Gordon, N. Edouard, and C. Vall. 2009. Instantaneous intake rate in horses of different body sizes: influence of sward biomass and fibrousness. Applied Animal Behavior Science 117:84-92.

Ganskopp, D., And M. VavRA. 1986. Habitat use by feral horses in the northern sagebrush steppe. Journal of Range Management 39:207-211.

GansKopp, D., And M. VavRA. 1987. Slope use by cattle, feral horses, deer, and bighorn sheep. Northwest Science 61:74-81.

Gillies, C. S., M. Hebblewhite, S. E. Nielsen, M. A. Krawchuk, C. L. Aldridge, J. L. Friar, D. J. Saher, C. E. Stevens, and C. L. Jerde. 2006. Application of random effects to the study of resource selection by animals. Journal of Animal Ecology 75:887898.

Girard, T. L., E. W. Bork, S. E. Nielsen, and M. J. Alexander. 2013. Landscape-scale factors affecting feral horse habitat use during summer within the Rocky Mountain foothills. Environmental Management 51:435-447.

Government of Alberta. 2010. C5-forest management plan, 2006-2026. Available at: http://www.srd.alberta.ca/ManagingPrograms/ForestManagement/ ForestManagementPlanning/ForestManagementPlans/documents/ ForestManagementUnitC5/FMU-C5-FMP.pdf. Accessed 15 February 2011.

GovernMENT OF AlberTA. 2011. Feral horses in Alberta. Available at: http://srd.alberta. $\mathrm{ca/LandsForests/LandManagement/FeralHorses/Default.aspx.} \mathrm{Accessed} 10$ September 2011.

Government of SASKatchewan. 2009. Bill 606: an act to protect the wild ponies of the Bronson Forest. Regina, SK, Canada: SK Government Publication Centre. 2 p.

HeBblewHITE, M. 2005. Predation by wolves interacts with the North Pacific Oscillation (NP0) on a western North American elk population. Journal of Animal Ecology $74: 226-233$

Henson, W. R. 1952. Chinook winds and red belt injury to lodgepole pine in the rocky mountain parks area of Canada. Forestry Chronicles 28:62-64.

Humane Society of the United States. 2005. Chapter 5: The Wild Horse Fertility Control Program. In: Human wildlife solutions. 1st ed. Washington, DC, USA: Humane Society Press. p. 63-75.

IRVING, D. B. 2001. The impacts of horse grazing on conifer regeneration in westcentral Alberta [PhD dissertation]. Edmonton, AB, Canada: University of Alberta. $155 \mathrm{p}$.

IvLEV, S. V. 1961. Experimental ecology of the feeding of fishes. New Haven, CT, USA: Yale University Press. $302 \mathrm{p}$.

JANIS, C. 1976. The evolutionary strategy of the equidae and the origins of rumen and cecal digestion. Evolution 30:757-774.

KaufMAnN, J. 2011. Interactions between cattle grazing and forestry on Alberta's public lands [MSc thesis]. Edmonton, AB, Canada: University of Alberta. $196 \mathrm{p}$.

Keren, E. N., and B. E. OLson. 2007. Applying thermal imaging software to cattle grazing winter range. Journal of Thermal Biology 32:204-211.

KNopfF, K. H. 2010. Cougar predation in a multi-prey system in west-central Alberta [PhD dissertation]. Edmonton, AB, Canada: University of Alberta. $271 \mathrm{p}$.

Kumar, L., A. K. SKIDMoRE, And E. Knowles. 1997. Modelling topographic variation in solar radiation in a GIS environment. International Journal Geographic Information Science 11:475-497.

Laliberte, A. S., and W. J. RipPle. 2004. Range contractions of North American carnivores and ungulates. Bioscience 54:123-138.

Launchbaugh, K. L., AND L. D. Howery. 2005. Understanding landscape use patterns of livestock as a consequence of foraging behaviour. Rangeland Ecology \& Management 58:99-108.
Linklater, W. L., E. Z. Cameron, E. O. Monit, and K. J. Stafford. 1999. Stallion harassment and the mating system of horses. Animal Behavior 58:295-306.

Lotek WiReLESS Inc. 2011. GPS 7000 series wildlife collars with remote communication. Available at: http://www.lotek.com/gps7000.htm. Accessed 9 March 2011.

Manly, B. F. J., L. L. McDonald, D. L. Thomas, T. L. McDonald, and W. P. ERickson. 2002. Resource selection by animals: statistical design and analysis for field studies. Dordrecht, The Netherlands: Kluwer Academic Publishers. 234 p.

McCort, W. D. 1984. Behavior of feral horses and ponies. Journal of Animal Science 58:493-499.

Mysterud, A., and E. Østbye. 1999. Cover as a habitat element for temperate ungulates: effects on habitat selection and demography. Wildlife Society Bulletin 27:385-394.

Natural Regions Committee. 2006. Natural regions and subregions of Alberta. Compiled by D. J. Downing and W. W. Pettapiece. Pub. No. T/852. Edmonton, AB, Canada: Government of Alberta. $264 \mathrm{p}$.

Perotto-Baldivieso, H. L., S. M. Cooper, A. F. Ciblls, M. Figueroa-Pagan, K. Udaeta, and C. M. BLACK-RuBio. Detecting autocorrelation problems from GPS collar data in livestock studies. Applied Animal Behaviour Science 136:117-125.

Rempel, R. S., And A. R. Rodgers. 1997. Effects of differential correction on accuracy of a GPS animal location system. Journal of Wildlife Management 61:525-530.

Riley, S. J., S. D. Degloria, and R. Elloot. 1999. A terrain ruggedness index that quantifies topographic heterogeneity. Intermountain Journal of Sciences 5:2327.

Rodgers, A. R., A. P. Carr, H. L. Beyer, L. Smith, and J. G. KIE. 2007. HRT: home range tools for ArcGIS. Thunder Bay, ON, Canada: Ontario Ministry of Natural Resources, Centre for Northern Forest Ecosystem Research. 35 p.

RodGeRS, A. R., AND J. G. KIE. 2010. HRT: home range tools for ArcGIS (draft). Thunder Bay, Ontario, Canada: ON Ministry of Natural Resources, Centre for Northern Forest Ecosystem Research. 29 p.

Salter, R. E., and R. J. Hudson. 1979. Feeding ecology of feral horses in western Alberta. Journal of Range Management 32:221-225.

Salter, R. E., and R. J. Hudson. 1980. Range relationships of feral horses with wild ungulates and cattle in western Alberta. Journal of Range Management 33:266271.

Salter, R. E., and R. J. Hudson. 1982. Social organization of feral horses in western Canada. Applied Animal Ethology 8:207-223.

Senft, R. L., M. B. Coughenour, D. W. Balley, R. L. Rittenhouse, O. E. Sala, and D. M. Swif. 1987. Large herbivore foraging and ecological hierarchies. BioScience 37:789-799.

Sheelar, M. D, and C. F. Veauvy. 1977. Detailed soil survey of Bragg Creek Area. Edmonton, AB, Canada: Alberta Institute of Pedology. $64 \mathrm{p}$.

Stevens, E. F. 1988. Contests between bands of feral horses for access to fresh water: the resident wins. Animal Behaviour 36:1851-1853.

Whittington, J., C. C. St. Clair, and G. Mercer. 2005. Spatial response of wolves to roads and trails in mountain valleys. Ecological Applications 15:543-553.

Willms, W. D., S. Smoliak, and J. F. DormaAR. 1985. Effects of stocking rate on rough fescue grassland vegetation. Journal of Range Management 38:220-225.

WindmeIJER, F. A. G. 1995. Goodness-of-fit measures in binary choice models. Econometrics Review 14:101-116. 